Vitor Monteiro, M. J. Sepúlveda, J. C. Aparício Fernandes, J. G. Pinto, João L. Afonso

"Evaluation of the Introduction of Electric Vehicles in the Power Grid - A Study for the Island of Maio in Cape Verde"

CONTROLO Portuguese Conference on Automatic Control, Guimarães - Portugal, Sept. 2016.

http://link.springer.com/chapter/10.1007\%2F978-3-319-43671-5 60

ISBN: 978-3-319-43670-8

DOI 10.1007/978-3-319-43671-5_60

This material is posted here according with:

"The Author may self-archive an author-created version of his/her Contribution on his/her own website and/or in his/her institutional repository, including his/her final version. He/she may also deposit this version on his/her funder's or funder's designated repository at the funder's request or as a result of a legal obligation, provided it is not made publicly available until 12 months after official publication."

(C) 2014 SPRINGER 
Vítor Monteiro, M. J. Sepúlveda, J. C. Aparício Fernandes, João L. Afonso, “Evaluation of the Introduction of Electric Vehicles in the Power Grid - A Study for the Island of Maio in Cape Verde", CONTROLO Portuguese Conference on Automatic Control, Guimarães Portugal, pp.713-724, Sept. 2016. DOI: 10.1007/978-3-319-43671-5_60 ISBN: 978-3-319-43670-8 (Print) 978-3-319-43671-5 (Online)

\title{
Evaluation of the Introduction of Electric Vehicles in the Power Grid - A Study for the Island of Maio in Cape Verde
}

\author{
Vitor Monteiro, M. J. Sepúlveda, J. C. Aparício Fernandes, \\ J. G. Pinto, João L. Afonso \\ Centro Algoritmi - University of Minho - Guimarães, Portugal \\ \{vitor.monteiro, sepulveda.freitas, aparicio.fernandes, \\ gabriel.pinto, joao.l.afonso\} dalgoritmi.uminho.pt
}

\begin{abstract}
This paper presents an evaluation of the introduction of electric vehicles (EVs) in an electrical power grid. The main contribution is the control analysis of the power quality considering simultaneous battery charging processes. The methodology used can be applied to any known power grid; however, it was considered the case of the island of Maio, in Cape Verde, in continuation of previous works concerning that power grid. Two commercial different types of battery chargers were considered: a traditional model with highly distorted current consumption (that causes distortion in the power grid voltage), and another with almost sinusoidal current consumption. Considering simultaneous battery charging processes, it can be concluded that the power grid structure (composed by three medium voltage branches) with the current power demands of the consumers of the island of Maio have a potential integration for $300 \mathrm{EVs}$ if battery chargers with almost sinusoidal current consumption are used, i.e., 152 for the first medium voltage branch, 35 for the second branch, and 113 for the third branch. Moreover, the results show that the first medium voltage branch of the distribution system, which has the capability to support the integration of $152 \mathrm{EVs}$ if the battery chargers have sinusoidal current consumption (presenting a maximum value of $\mathrm{THD}_{\mathrm{v}} \%$ in the power grid voltage of $1.8 \%$ ), only can support $27 \mathrm{EVs}$ if are used traditional battery chargers, with highly distorted current consumption (considering a maximum THD $\%$ of $5 \%$ ).
\end{abstract}

Keywords: Cape Verde; Electric Vehicle; Harmonic Distortion; Power Quality.

\section{Introduction}

The vehicles with internal combustion engines (ICE) in use in the transportation systems are responsible for a large amount of $\mathrm{CO}_{2}$ emissions, and this is a major concern. Also it is estimated that $55 \%$ of the total oil consumption in the world in 2030 will be in the transportation sector [1]. It is envisaged the use of electric motors in order to diminish not only the output of greenhouse gases such as the $\mathrm{CO}_{2}$ but also to minimize both the fuel and the lubricant oil consumptions that ICE imposes. Although the 
avoidance of $\mathrm{CO}_{2}$ exhaust is not fully avoided in the general picture, because electric power needs to be generated and in most cases ICE systems are employed, it can be a much lower emission situation by burning fossil fuels at a more efficient power plant (and at a larger distance from the intense human occupation cities where transportation is needed). Also a more efficient power usage in the traction is possible using electric instead of ICE. The actual practical motoring solutions are the electric vehicles (EV) and plug-in hybrid electric vehicles (PHEV). Hydrogen based systems and others have not been shown, at least not yet, viable economic proposals. Some of these alternatives are already available in the market such as Nissan Leaf (EV) or Toyota Prius (PHEV). These vehicles allow performing the battery charging from a standard outlet (public or private). In this case the energy flows from the power grid to the batteries. This method is denominated grid-to-vehicle (G2V). However, from the moment that the vehicle is plugged in to the power grid, theoretically, the energy may flow in bidirectional way (vehicle-to-grid, V2G). The V2G operation may be a key technology in the future smart grids [2,3]. Focusing the smart grids, in [4] is analyzed the upcoming power grid considering the introduction of EVs and PHEVs. In this scenario, in [5] the advances of a concrete project to integrate EVs into smart grids are presented. In this project is also analyzed the possible integration of renewable energies as a contribution to the EV battery charging process. In this context, EVs can play an important role to smoothing the natural intermittency of the renewable energies through the operation as energy storage system. Besides these contributions, the EVs can also be used to ensure the power grid stability in terms of voltage and frequency. Nevertheless, depending of the topology of the battery charger, the introduction of EVs can bring problems to the power grid, contributing to the degradation of the power quality [6]. In [7] and [8] are presented studies that analyze the impact of the introduction of EVs at residential level. From these studies it may be concluded that the simultaneously battery charging process can cause power quality problems. Thereby, the actual power grids are facing new challenges, mainly taking into account the different energy storage systems [9], and their integration [10]-[13]. Considering the pros and cons of the EVs integration, in this paper is evaluated the impact of the EV battery charging process in the power grid of the island of Maio in Cape Verde. This island is part of the leeward group of islands of Cape Verde archipelago and it has about 9000 inhabitants and an area of $269 \mathrm{~km}^{2}$ (length of $31 \mathrm{~km}$ and width of $25 \mathrm{~km}$ ). Although this study has been conducted to the island of Maio, the method used may also be employed in other known power grid. In this paper it is mainly analyzed the influence in the power grid voltage along the distribution grid. Two different types of EV battery chargers were considered: a traditional battery charger with high level of total harmonic distortion; and a battery charger with sinusoidal current consumption.

\section{Power Grid of the Island of Maio in Cape Verde}

In order to characterize and obtain reliable data related with the power grid in the island of Maio in Cape Verde, it was conducted an inquiry in the residential and in- 
Table 1. Energy production (MWh) in the archipelago off Cape Verde, from 2006 to 2010, according to the different types of energy generation.

\begin{tabular}{|c|c|c|c|c|c|}
\hline & $\mathbf{2 0 0 6}$ & $\mathbf{2 0 0 7}$ & $\mathbf{2 0 0 8}$ & $\mathbf{2 0 0 9}$ & $\mathbf{2 0 1 0}$ \\
\hline Type of Generation & \multicolumn{5}{|c|}{ Energy Production (MWh) } \\
\hline Diesel & 241709 & 260465 & 279645 & 290273 & 314315 \\
\hline Solar Photovoltaic & 0 & 0 & 0 & 0 & 2105 \\
\hline Wind & 7441 & 6869 & 5510 & 4661 & 1992 \\
\hline Steam & 1772 & 1185 & 640 & 0 & 0 \\
\hline
\end{tabular}

dustrial sectors. Thus, this section is divided in two parts: the power grid structure and the EV current consumption profile. The description of both parts is made in accordance with the data provided by ELECTRA SARL, which is a company that has as aim the production, transport and distribution of electricity across the territory of Cape Verde [14].

The distribution power grid in Cape Verde is divided in medium and low voltage. In medium voltage (MV) the nominal voltage is $20 \mathrm{kV}$, and in low voltage (LV) the nominal voltage is $220 \mathrm{~V}$ (phase-neutral). According to the inquiry, $19 \%$ of the industrial sector is connected to the power grid in LV and $81 \%$ in MV [15]. Another important fact that results from this inquiry in the industrial sector is that $30 \%$ compensates reactive power, $61 \%$ does not compensate, and $9 \%$ does not have knowledge about it [15]. In 2010 starts the construction of a substation in the Santiago island in order to distribute energy in high voltage (HV) $60 \mathrm{kV}$, and aiming to integrate some isolated grids. From the inquiry, both to the residential and industrial sectors, it was concluded that $18 \%$ classifies as good the energy distribution system, $30 \%$ classifies as bad, and $52 \%$ classifies as acceptable [15]. Related with the energy production, in Table 1 are presented the values of the energy production (MWh) according to the different types of generation, from 2006 to 2010. In Cape Verde the energy production is essential based on synchronous generators. This table shows that the diesel production has increased, meaning that the greenhouse effect gases also have increased. However, taking into account the geographic and climatic location of Cape Verde, it has a large potential to the renewable energy introduction, mainly photovoltaic and wind. In this context, from 2010 starts the photovoltaic production [15]. Besides the aforementioned inquiry, the power grid voltage was monitored in the residential (private) and industrial sector (SITA - Sociedade Industrial de Tintas, SA), aiming to register their variations along 5 and 14 days, respectively. For such purpose it was used the equipment VLog Q from LEM, which allows to determine power quality parameters according to the NP EN 50160 standard. This equipment was programmed to register the parameters at each 5 minutes. The minimum registered value was $173.6 \mathrm{~V}$, and the maximum 224.5 V. During this period three power outages were registered, which occurred in the same day, with 7 hours 2 minutes and 14 seconds (first outage), 14 seconds (second outage), and 2 minutes and 6 seconds (third outage). The minimum registered value (in an industry along 14 days) was $178.3 \mathrm{~V}$, and the maximum $249.5 \mathrm{~V}$. In this case four power outages were registered, two during 20 seconds and two during 5 seconds. Besides the registration of the voltage RMS values variation, it was also registered the $\mathrm{THD}_{\mathrm{v}} \%$ of the power grid voltage. In the residence the $\mathrm{THD}_{\mathrm{v}} \%$ registered was $3.5 \%$ and in the industry was $1.6 \%$. 


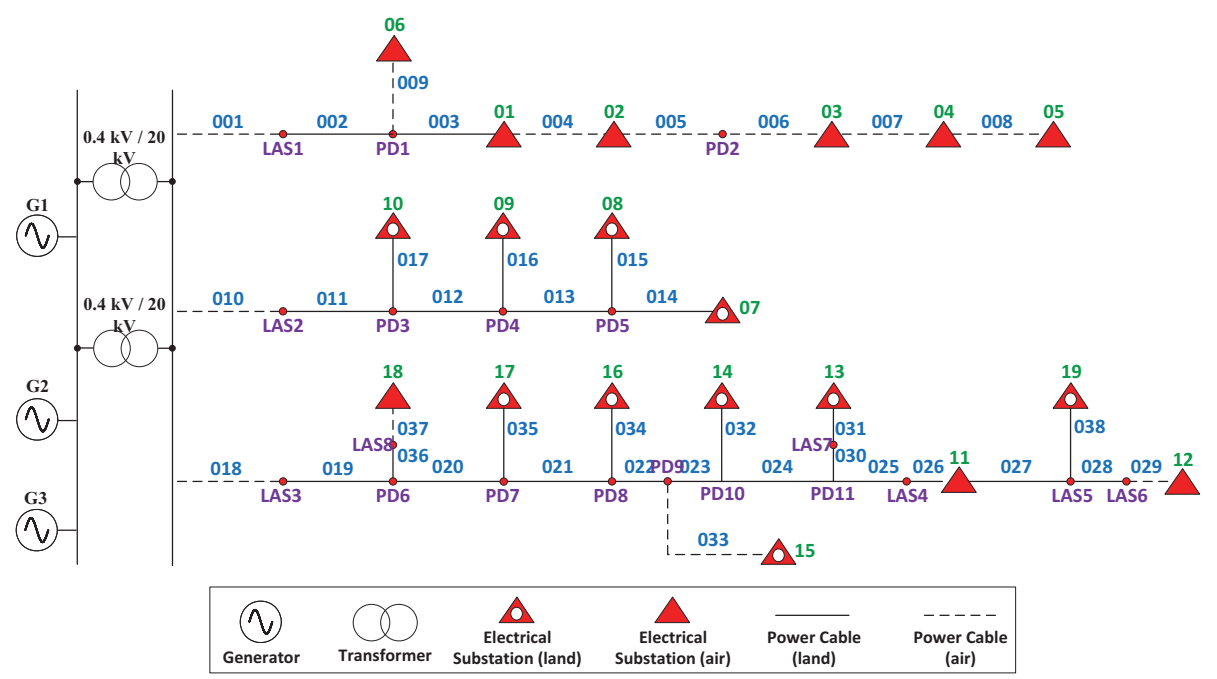

Fig. 1. Medium voltage single-line power grid diagram of the island of Maio in Cape Verde.

Table 2. Nominal power and voltages (MV side) in each distribution transformer.

\begin{tabular}{|c|c|c|c||c|c|c|c|}
\hline \hline $\begin{array}{c}\text { Distribution } \\
\text { Transformer }\end{array}$ & Location & $\begin{array}{c}\text { Power } \\
(\mathbf{k W})\end{array}$ & $\begin{array}{c}\text { Voltage } \\
(\mathbf{k V})\end{array}$ & $\begin{array}{c}\text { Distribution } \\
\text { Transformer }\end{array}$ & Location & $\begin{array}{c}\text { Power } \\
(\mathbf{k W})\end{array}$ & $\begin{array}{c}\text { Voltage } \\
(\mathbf{k V})\end{array}$ \\
\hline \hline DT01 & Shell & 80.3 & 19.97 & DT11 & Pedro Vaz & 19.4 & 19.88 \\
\hline DT02 & Cemiterio & 16.6 & 19.96 & DT12 & Alcatraz/Pilão Cão & 9.4 & 19.88 \\
\hline DT03 & Estella Maris & 8.2 & 19.96 & DT13 & Cascabulho & 7.2 & 19.89 \\
\hline DT04 & Farol & 105.2 & 19.95 & DT14 & Morrinho & 10.5 & 19.90 \\
\hline DT05 & Fontona & 55.4 & 19.95 & DT15 & Centro Zootecnico & 8.3 & 19.90 \\
\hline DT06 & Centro Formação & 5.5 & 19.97 & DT16 & Calheta & 36.0 & 19.91 \\
\hline DT07* & Ribeira Don João & - & - & DT17 & Morro & 8.9 & 19.95 \\
\hline DT08 & Figueira Seca & 5.5 & 19.98 & DT18 & Bela Vista & 16.6 & 19.95 \\
\hline DT09 & Figuiera Horta & 9.4 & 19.98 & DT19* & Praia Gonçalo & - & 19.88 \\
\hline DT10 & Barreiro & 10.5 & 19.99 & * Out of operation. & & \\
\hline \hline
\end{tabular}

\subsection{Description of the Power Grid Structure}

In this item is described the power grid structure. Fig. 1 represents the single-line diagram of the medium voltage (MV) power grid. It is important to refer that just one of the transformers is used. The other transformer is installed, however, it is only used as a substitute. Another important parameter that was included in this description is the line impedance. This parameter is extremely important to analyze the voltage distortion along the power grid (from the generation until the more distant distribution transformer). Due to the line impedance and the consumed current profile, the power grid voltage is more affected in the longest power lines, where this power quality problem can cause problems of malfunctioning in the connected loads. Table 2 shows the nominal power and voltages (MV side) in each distribution transformer and Table 3 shows the characteristics of each line of the island of Maio. 
Table 3. Characteristics of each line of the island of Maio.

\begin{tabular}{|c|c|c|c|c|c|c|}
\hline Line & Type & Conductor & $\begin{array}{c}\text { Length } \\
\text { (m) }\end{array}$ & $\begin{array}{c}\text { Resistance } \\
(\Omega)\end{array}$ & $\begin{array}{c}\text { Inductance } \\
(\mathrm{mH})\end{array}$ & $\begin{array}{c}\text { Capacitance } \\
(\mu \mathrm{F})\end{array}$ \\
\hline 001 & underground & copper & 100 & 0.0727 & 0.0399 & 0.0150 \\
\hline 002 & aerial & ACSR & 1000 & 0.9593 & 1.2319 & \\
\hline 003 & underground & copper & 200 & 0.1454 & 0.0799 & 0.0300 \\
\hline 004 & underground & copper & 551 & 0.2132 & 0.2093 & 0.0827 \\
\hline 005 & underground & aluminum & 290 & 0.2384 & 0.1274 & 0.0522 \\
\hline 006 & underground & copper & 250 & 0.1818 & 0.0999 & 0.0375 \\
\hline 007 & underground & copper & 884 & 0.6427 & 0.3534 & 0.1326 \\
\hline 008 & underground & copper & 550 & 0.3999 & 0.2199 & 0.0825 \\
\hline 009 & underground & copper & 80 & 0.0582 & 0.0319 & 0.0139 \\
\hline 010 & underground & copper & 100 & 0.0727 & 0.0399 & 0.0160 \\
\hline 011 & aerial & ACSR & 3580 & 3.4343 & 4.4101 & \\
\hline 012 & aerial & ACSR & 2850 & 2.7340 & 3.5108 & \\
\hline 013 & aerial & ACSR & 680 & 0.6523 & 0.8377 & \\
\hline 014 & aerial & ACSR & 2650 & 2.5421 & 3.2644 & \\
\hline 015 & aerial & ACSR & 120 & 0.1151 & 0.1478 & \\
\hline 016 & aerial & ACSR & 350 & 0.3358 & 0.4312 & \\
\hline 017 & aerial & ACSR & 250 & 0.2398 & 0.3079 & \\
\hline 018 & underground & copper & 40 & 0.0291 & 0.0159 & 0.0060 \\
\hline 019 & aerial & ACSR & 4530 & 4.3456 & 5.5803 & \\
\hline 020 & aerial & ACSR & 500 & 0.4797 & 0.6159 & \\
\hline 021 & aerial & ACSR & 5640 & 5.4105 & 6.9477 & \\
\hline 022 & aerial & ACSR & 1900 & 1.8227 & 2.3405 & \\
\hline 023 & aerial & ACSR & 1560 & 1.4965 & 1.9217 & \\
\hline 024 & aerial & ACSR & 3480 & 2.1158 & 4.1318 & \\
\hline 025 & aerial & ACSR & 7499 & 4.5594 & 8.9035 & \\
\hline 026 & underground & copper & 30 & 0.0116 & 0.0114 & 0.0048 \\
\hline 027 & underground & copper & 35 & 0.0135 & 0.0133 & 0.0056 \\
\hline 028 & aerial & ACSR & 4500 & 4.3169 & 5.5434 & \\
\hline 029 & underground & copper & 15 & 0.0058 & 0.0057 & 0.0024 \\
\hline 030 & aerial & ACSR & 332 & 0.2019 & 0.3942 & \\
\hline 031 & underground & aluminum & 30 & 0.0039 & 0.0063 & 0.0054 \\
\hline 032 & aerial & ACSR & 300 & 0.2878 & 0.3696 & \\
\hline 033 & underground & aluminum & 860 & 0.7069 & 0.3778 & 0.1548 \\
\hline 034 & aerial & ACSR & 350 & 0.3358 & 0.4312 & \\
\hline 035 & aerial & ACSR & 250 & 0.2398 & 0.3079 & \\
\hline 036 & aerial & ACSR & 1200 & 1.1512 & 1.4782 & \\
\hline 037 & underground & copper & 20 & 0.0105 & 0.0139 & 0.0035 \\
\hline 038 & aerial & ACSR & 2024 & 1.2306 & 2.4031 & \\
\hline
\end{tabular}

\subsection{Description of the Different Battery Chargers}

This section describes in detail the battery chargers that were considered in this paper. Taking into account that the main goal of this paper is analyze the potential impacts of the battery chargers on the power quality, two different types of battery chargers were considered. The first is a traditional unidirectional battery charger with highly distorted current consumption [16]. Fig. 2(a) shows the grid current and Fig. 2(b) the spectral analysis and the $\mathrm{THD}_{\mathrm{i}} \%$. The second is also a unidirectional battery charger, however with unitary power factor and sinusoidal current consumption. It was used the Renault Fluence EV as an example [17]. Fig. 3(a) shows the grid current and Fig. 3(b) shows spectral analysis and the $\operatorname{THD}_{\mathrm{i}} \%$. 
(a)

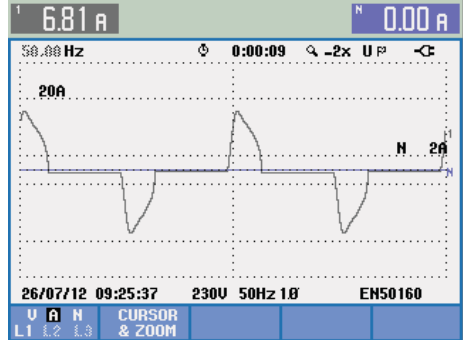

(b)

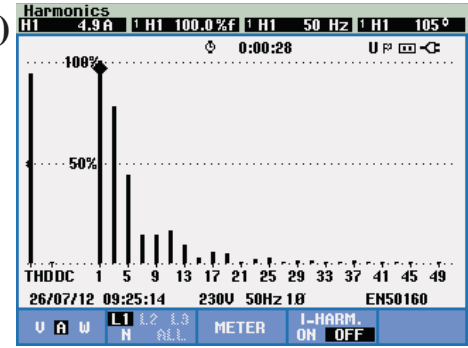

Fig. 2. Traditional unidirectional battery charger: (a) Power grid current; (b) Spectral analysis and $\mathrm{THD}_{\mathrm{i}} \%$.

(a)

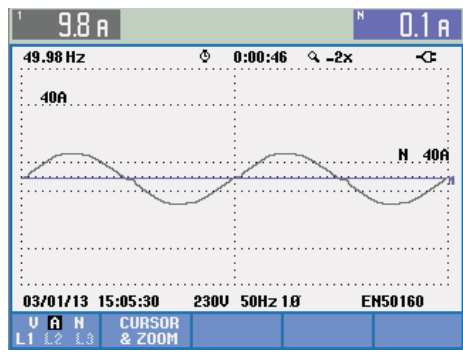

(b)

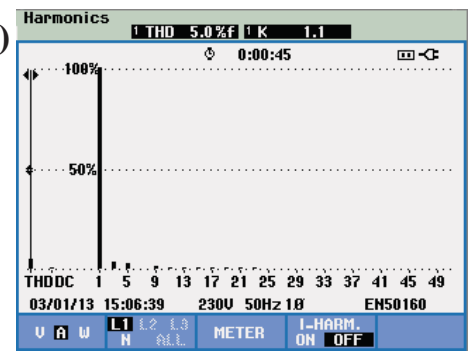

Fig. 3. Unidirectional battery charger with sinusoidal current consumption:

(a) Power grid current; (b) Spectral analysis and $\mathrm{THD}_{\mathrm{i}} \%$.

\section{Simulation of the Power Grid Operation}

In order to analyze the potential impacts of the EVs battery chargers in the power grid, mainly their impact in terms of power quality, several simulations using the simulation tool PSIM 9.1 were performed. The power grid structure (subsection II.A), and the introduction of different battery chargers (section II.B) were included in the simulation model. In the simulation model, the electrical appliances are composed by linear (resistances and inductances) and nonlinear loads (diode bridge rectifiers with output capacitive filter and resistive load). The EV battery charger are composed by two topologies: diode bridge rectifiers with output capacitive filter and resistive load (without sinusoidal current consumption); full-bridge full-controlled active rectifier (with sinusoidal current consumption). This item is divided in two parts: power grid without EVs; and power grid with EVs connected in coordinated and uncoordinated way. In the controlled way, the battery charging process occurs in accordance with the power grid capabilities and also considering the EV driver benefits, like the schedules where the energy is cheaper. On the other hand, in the uncontrolled way, which is the most common charge procedure, each EV can be connected to the power grid neglecting the power grid capabilities. These processes are further presented in detail.

\subsection{Power Grid without EVs}

Taking into account the aforementioned loads in this item are presented the power grid voltage and the consumed current considering the power grid without EVs. Fig. 4(a) shows the obtained results of the power grid voltage $(217.82 \mathrm{~V})$ and the line 

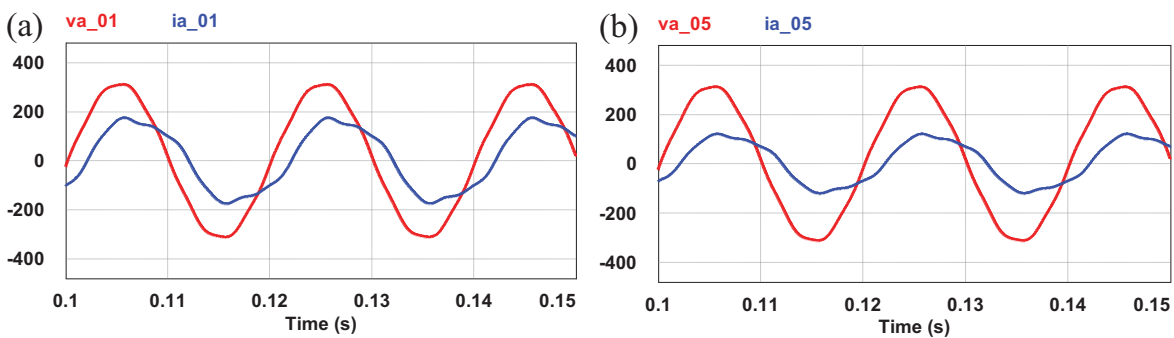

Fig. 4. Power grid voltage and consumed current considering the power grid without EVs in:

(a) Distribution Transformer DT01; (b) Distribution Transformer DT05.

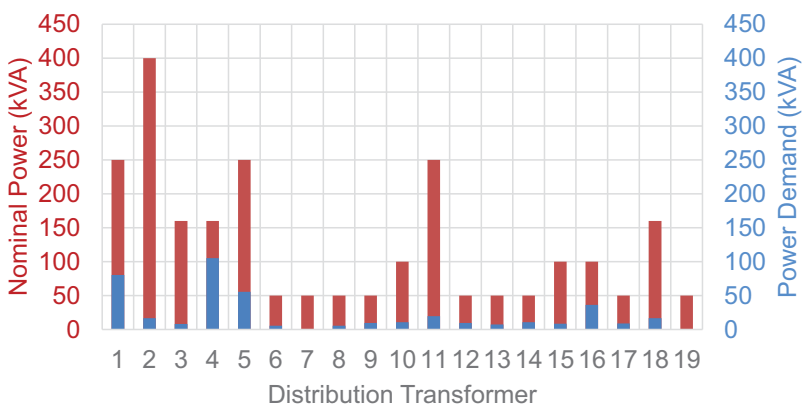

Fig. 5. Nominal power (kVA) and power demand (kVA) for each distribution transformer.

current $(122.90 \mathrm{~A})$ in the distribution transformer DT01, which is the beginning of the line. In this case the lagging power factor is 0.88 and the voltage $\mathrm{THD}_{\mathrm{v}} \%$ and current $\mathrm{THD}_{\mathrm{i}} \%$ are $1.83 \%$ and $12.14 \%$, respectively. On the other side, Fig. $4(\mathrm{~b})$ shows the power grid voltage $(218.15 \mathrm{~V})$ and the line current $(84.79 \mathrm{~A})$ in the distribution transformer DT05, which is the end of the line. In this case the lagging power factor is 0.88 and the voltage $\mathrm{THD}_{\mathrm{v}} \%$ and current $\mathrm{THD}_{\mathrm{i}} \%$ is $1.78 \%$ and $12.14 \%$, respectively. Considering that the distance between the Distribution Transformer DT01 and DT05 is about $3.8 \mathrm{~km}$ and the low power (i.e., it was simulated the power grid only with the loads) the $\mathrm{THD}_{\mathrm{v}} \%$ in both distribution transformers is almost equal. This situation occurs in all the power grid.

\subsection{Power Grid with EVs}

Considering the EVs integration in the power grid, the battery charging process can be performed in two different ways: coordinated or uncoordinated. The coordinated battery charging process is performed in accordance with the power grid capabilities in real time, and also taking into account the driver convenience. Thus, it must be considered the period of the day, the energy price to sell or buy and the remaining energy stored in the batteries (state-of-charge). On the other hand, with the uncoordinated way, the battery charging process is performed immediately or after a fixed time delay. This is the most common charge procedure, however, it can strength a large peak of power demand from the power grid. Considering the maximum power of each distribution transformer and the power demand for the connected loads, it was analyzed the maximum number of EVs that can be introduced simultaneous in each one. Fig. 5 shows the nominal power $(\mathrm{kVA})$ and the power demand $(\mathrm{kVA})$ for each distribution transformer. From Fig. 5 it can be concluded that only the distribution 


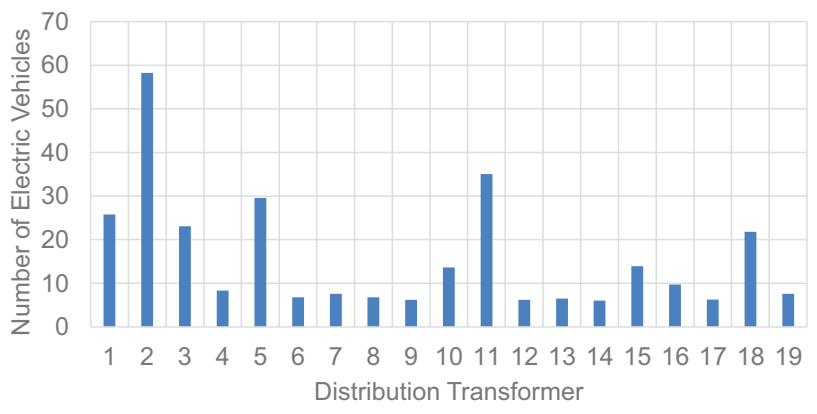

Fig. 6. Hypothetical number of EVs that can be introduced in each distribution transformer.
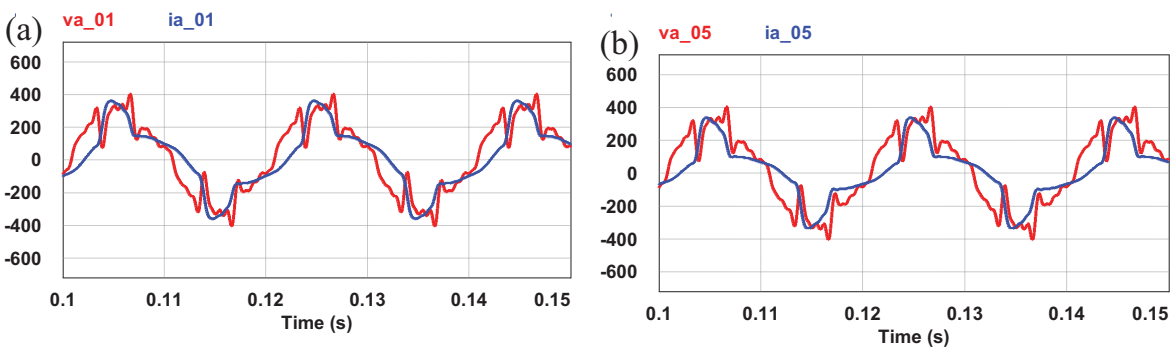

Fig. 7. Power grid voltage and current waveforms for the first branch considering the integration of 152 EVs without sinusoidal current consumption:

(a) In the distribution transformer DT01; (b) In the distribution transformer DT05.

transformer DT04 is used more than half of the nominal power. On the other side, the distribution transformer DT02 is the least used in terms of nominal power. Taking into account the aforementioned battery chargers and that the maximum consumed current is $10 \mathrm{~A}$ (rms value), in Fig. 6 is shown the hypothetical maximum number of EVs that can be introduced in each distribution transformer. Globally, it can be introduced nearly 300 vehicles. The EVs were introduced in each distribution transformer through the three branches according to the hypothetical number of EVs. The introduction of the number of EVs represented in Fig. 7 is the worst case. This situation was simulated in order to analyze the potential impacts of the two different battery chargers on the power quality. Fig. 7 also shows the power grid voltage and the current waveforms but considering the integration of EVs without sinusoidal current consumption: (a) in the distribution transformer DT01; and (b) in the distribution transformer DT05. On the other hand, Fig. 8 shows the power grid voltage and the current waveforms considering the integration of EVs with sinusoidal current consumption: (a) in the distribution transformer DT01; and (b) in the distribution transformer DT05. The value of $\mathrm{THD}_{\mathrm{v}} \%$ obtained with the introduction of EVs with highly distorted current consumption $\left(\mathrm{THD}_{\mathrm{v}} \% \approx 27 \%\right.$ ) is much greater than the $\mathrm{THD}_{\mathrm{v}} \%$ with the introduction of EVs with sinusoidal current consumption $\left(\mathrm{THD}_{\mathrm{v}} \% \approx 2 \%\right)$. However, the value of $\mathrm{THD}_{\mathrm{v}} \%$ in the first case is very high and can cause malfunctioning in other equipment connected to the power grid. Thus, in order to obtain a maximum value of $\mathrm{THD}_{\mathrm{v}} \%=5 \%$ the maximum number of EVs with highly distorted current consumption that can be connected simultaneously, from the distribution transformer DT01 to the DT06, are 27 . This value represents $18 \%$ of the hypothetical number of EV (152) that can be introduced in the referred distribution transformers. Clearly, these EVs can be distributed through these distribution transformers in several ways. 

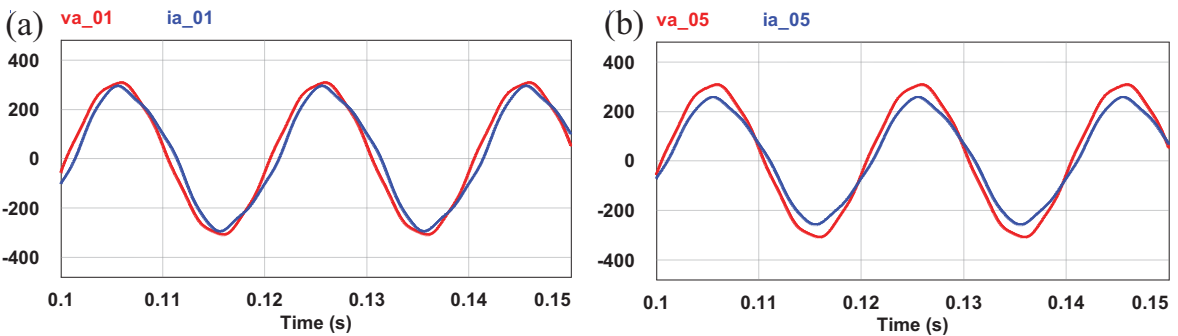

Fig. 8. Power grid voltage and current waveforms for the first branch considering the integration of 152 EVs with sinusoidal current consumption: (a) In the distribution transformer DT01;

(a) va_01 ia_01

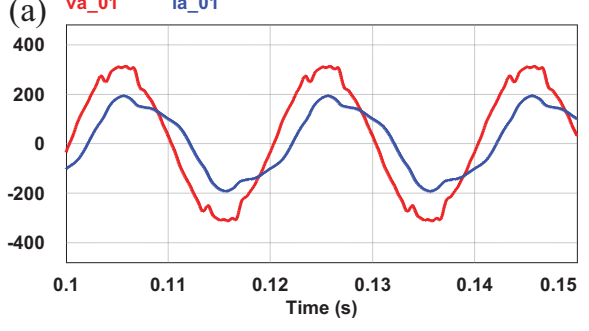

(b) In the distribution transformer DT05.

(b) va_05 ia_05

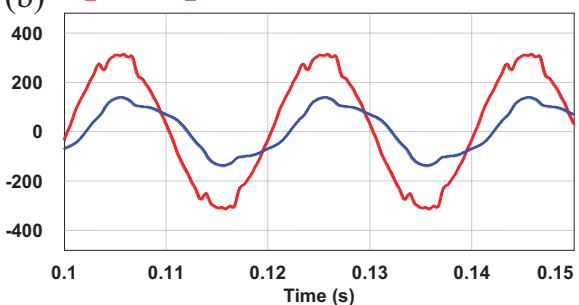

Fig. 9. Power grid voltage and current waveforms for the first branch considering the integration of 27 EVs without sinusoidal current consumption:

(a) In the distribution transformer DT01; (b) In the distribution transformer DT05.

Fig. 9 shows the power grid voltage and the current waveforms: (a) in the distribution transformer DT01; and (b) in the distribution transformer DT05.

\section{Conclusion}

In this paper were presented studies to evaluate the impact of the introduction of electric vehicles (EVs) in the power grid of the island of Maio, in Cape Verde. It was assessed the impact derived from the utilization of two different types of battery chargers, with highly distorted current consumption and with almost sinusoidal current consumption. Considering the current power demand and the power grid structure composed by three medium voltage branches, a hypothetical number of $300 \mathrm{EVs}$ (152 for the first branch, 35 for the second branch and 113 for the third branch) were able to perform the battery charging processes at the same time, if properly distributed in the power grid, and using battery chargers with almost sinusoidal current consumption. Considering only the first medium voltage branch, charging $152 \mathrm{EVs}$ at the same time using battery chargers with sinusoidal current consumption results in a maximum value of $\mathrm{THD}_{\mathrm{v}} \%$ of only $1.8 \%$, while charging the same number of EVs at the same time using battery chargers with highly distorted current consumption results in a maximum value of $\mathrm{THD}_{\mathrm{v}} \%$ of $27.5 \%$, which is a totally unacceptable situation. Also for the first medium voltage branch, using battery chargers with highly distorted current consumption, and limiting the maximum value of $\mathrm{THD}_{\mathrm{v}} \%$ to $5 \%$, would result in the charging at the same time of a maximum of only 27 EVs (less than $1 / 5$ of the number of EVs that could be charged using battery chargers with sinusoidal current consumption). 


\section{Acknowledgements}

This work has been supported by COMPETE: POCI-01-0145-FEDER-007043 and FCT - Fundação para a Ciência e Tecnologia within the Project Scope: UID/CEC/00319/2013. The PhD student Vítor Monteiro was supported by the doctoral scholarship SFRH/BD/80155/2011 granted by the FCT agency.

\section{References}

1. "International Energy Outlook 2009," Energy Information Administration Office of Integrated Analysis and Forecasting U.S. Department of Energy Washington DC, (2009).

2. Monteiro, V., Pinto, J. G., Afonso, J. L.: Operation Modes for the Electric Vehicle in Smart Grids and Smart Homes: Present and Proposed Modes. In IEEE Transactions on Vehicular Technology, vol.65, no.3, pp.1007-1020, Mar. 2016.

3. Han, S., Han, S., Sezaki, K.: Development of an Optimal Vehicle-to-Grid Ag-gregator for Frequency Regulation. In IEEE Trans. Smart Grid, vol.1, pp.65-72, (2010).

4. Ipakchi, A., Albuyeh, F.: Grid of the Future. In IEEE Power \& Energy Magazine, (2009).

5. Hernandez, S. S., Galindo, P. P., Lopez, A. Q.: EPV PROJECT. Technology to integrate EV inside smart grids. In IEEE Conference on the European Energy Market (2010).

6. Gomez, J. C., Morcos, M. M.: Impact of EV Battery Chargers on the Power Quality of Distributed Systems. In IEEE Trans. Power Delivery, vol.18, no.3, pp.975, (2003).

7. Lambert, F.: Secondary Distribution Impacts of Residential Electric Vehicle Charging. In California Energy Commission, (2000).

8. Morcos, M. M., Dillman, N. G., Mersman, C. R.: Battery Chargers for Electric Vehicles. In IEEE Power Engineering Review, vol.20, no.11, pp.8-11, (2002).

9. Khaligh, A., Zhihao, L.: Battery, Ultracapacitor, Fuel Cell, and Hybrid Energy Storage Systems for Electric, Hybrid Electric, Fuel Cell, and Plug-In Hybrid Electric Vehicles: State of the Art. In IEEE Trans. Vehicular Technology, vol.59, pp.2806-2814, (2010).

10. Monteiro, V., Gonçalves, H., Afonso, J. L.: Impact of Electric Vehicles on Power Quality in a Smart Grid Context. In IEEE EPQU International Conference on Electrical Power Quality and Utilization, Portugal, (2011).

11. Joos, G., Dubois, M. R.: Integration of PHEVs and EVs Experience from Canada. In IEEE PES Power and Energy Society General Meeting, pp.1-5, (2010).

12. Bertling, L., Carlson, O., Lundmark, S., Steen, D.: Integration of Plug-In Hybrid Electric Vehicles and Electric Vehicles - Experience from Sweden. In IEEE PES Power and Energy Society General Meeting, pp.1-3, (2010).

13. Song, Y., Yang, X., Lu, Z., Integration of Plug-in Hybrid and Electric Vehicles Experience from China. In IEEE PES Power and Energy Society General Meeting, pp.1-6, (2010).

14. Electra SARL, "Empresa" Available [online], 21 October 2013, http://www.electra.cv/index.php/Empresa.html

15. Samira dos Santos Andrade, "Qualidade de Energia Elétrica e Impacto das Energias Renováveis em Cabo Verde,” M.Sc. Dissertation, University of Minho, Portugal, (2012).

16. Battery Charger, "Piktronik KOP1001," Available [online], 16 October 2013, $\mathrm{http}: / /$ www.piktronik.com/index.php?option=com_content\&view=article\&id=33\&Itemid= $105 \&$ lang $=$ en

17. Renault Fluence, Available [online], 16 October 2013, http://www.renault.pt/gama/veiculos-de-passageiros/fluence/novo-fluence/apresentacao/ 